\title{
A SECOND STUDY OF BLASTING RECORDED IN SOUTHERN CALIFORNIA
}

\author{
By Harry O. Woon and Charles F. Richter \\ With a Note by Hugo BeniofF
}

Since the publication of our paper entitled "A Study of Blasting Recorded in Southern California"1 one further large blast has been set off in this region, and others moderate, to comparatively small, in magnitude. Two of these especially have afforded opportunity for further direct investigation. Others have yielded additional information.

1. On the afternoon of August 4, 1931, a blast consisting of a little more than 800 pounds (say 360 kilograms) of 20 per cent dynamite, buried in scattered charges at a depth of about 16 feet (5- meters) in weathered granitic rock, was set off simultaneously as a single charge at a location on a new road under construction along the mountain side above the Arroyo Seco almost due north from the Seismological Laboratory in Pasadena. This blast was registered usefully at the Laboratory and at the seismologic station on Mount Wilson, at distances between 12.5 and 13.5 kilometers (7.8- to 8.4- miles) from the road cut.

Through the courtesy of the contractors, the T. M. Morgan Paving Company, we were permitted to fire this blast and thus to control and determine the time of its detonation by a method indicated below.

2. On September 12, 1931, at 11 :01 a.m., P.S.T. (19:01 G.C.T.), a blast consisting of slightly more than twenty tons of high explosive was detonated in crystalline limestone at the site of a new quarry of the Southwestern Portland Cement Company 8.5 kilometers (5.3miles) northeast of their plant near Victorville, California. This was registered usefully at a temporary station at this plant, and at the seismologic stations of our local network at Riverside, Mount Wilson, Pasadena, Haiwee, and Tinemaha, at distances ranging from 8.5 up to about 290 kilometers ( 5.3 - to 180 - miles) from the quarry.

Through the cordial co-operation of Mr. L. V. Robinson, Superintendent, of the Southwestern Portland Cement Company at Victorville,

\footnotetext{
${ }^{1}$ Harry O. Wood and Charles F. Richter, "A Study of Blasting Recorded in Southern California," Bulletin of the Seismological Society of America, 21, 28-46, March, 1931.
} 
of Mr. F. C. Hubbard, in charge for the Southern Sierras Power Company at Victorville, and of Mr. Eugene G. Rudd, wire chief of the telephone company at Victorville, we were enabled to time accurately the instant when this blast was detonated, by methods described below.

3. Minor blasts have been registered from other sources-notably a rock cut near the Eagle Rock only about $0.8+$ mile ( 1.34 kilometers) a little south of west from the Seismological Laboratory. These have afforded checks in some instances, and a little additional information.

For a number of courtesies in connection with these blasts we are indebted to the Edwards Construction Company.

\section{The Arroyo Seco Blast}

Information that this blast was to be fired was given to us a short time in advance, but the exact date and time remained in uncertainty until the day previous to the firing. Consequently our own plans were correspondingly uncertain, and the more desirable and refined methods for timing it were not practicable in this case.

The location of the explosive was stated by the engineers in charge of the work to be $\phi=34^{\circ} 15^{\prime} 20^{\prime \prime} \mathrm{N}$., $\lambda=118^{\circ} 11^{\prime} 40^{\prime \prime}$ W., with an error not exceeding $10^{\prime \prime}(300+$ meters, or a little more than 1,000 feet). As determined by the engineers from the topographic map, this point is at an elevation of 2,940 feet (nearly 900 meters) above sea, on the Tujunga Quadrangle of the United States Geological Survey.

With the instrumental apparatus available the following procedure was adopted. Eleven hundred feet (335 meters) south of the site of the blast, across a depression or gully 200 feet (61 meters) deep, was placed a vertical-component portable seismometer or shock-detector of electro-magnetic type. Shock waves from the blast disturbed this sensitive instrument and its response was communicated over telephone wires to the Seismological Laboratory, where it was marked automatically on all the seismograms, and also upon a continuous radio-time-comparison record written there. (A similar continuous radio-time-comparison record was written at the Mount Wilson station.) The method for accomplishing this direct timing is described immediately below.

The following note is contributed by Mr. Hugo Benioff of the Seismological Laboratory staff.

A method for timing blasts.- "A vertical seismometer is placed as near the site of the blast as is convenient. The coils of the seismometer are direct-connected to a vacuum-tube amplifier whose output operates a high-speed relay. The relay operates a small buzzer which gives out 
a note of approximately 500 -cycles pitch. The relay is arranged in a special slow-release circuit so that it remains in contact throughout the time during which the earth movements are greater than a predetermined value. The buzzer is placed near a telephone mouthpiece so that its sound is transmitted by telephone connection to the recording station. At the recording station the buzzer signal is amplified by a two-stage tube amplifier and then rectified by a tube detector. Rectification is necessary since the received signal is an alternating current. The output of the detector operates a high-speed relay which in turn supplies power to the recording time-markers."

It is estimated that the total lag between the arrival of the earth motion at the shock-detector and operation of the recording time-markers at the Seismological Laboratory did not exceed one-fiftieth of a second.

The shock waves from the blast were recorded on the seismograms at Pasadena a little later than the signal from the shock-detector. Shock waves were also recorded at Mount Wilson. In both cases the straightline path from blast site to station is through air for all but a negligible part of the way, but a shallow curved path through rock is to be expected and such a path is readily available. In both instances the path lies almost certainly in granitic rock for the entire distance.

The air-line distance from the explosive to the shock-detector was 1,100 feet (335 meters), very closely. The path through the earth, here weathered but firm, undisintegrated granitic rock, almost certainly was not more than 1,200 feet (366 meters). On this account, therefore, the time of detonation was earlier than the time registered by the shockdetector by an amount not less than 0.061 of a second and not greater than 0.073 of a second, taking limits of distance as 1,100 and 1,200 feet and limits of wave-speed as 5.0 and 5.5 kilometers $(3.1+$ and $3.4+$ miles) per second.

Further, the blast was set off, as exactly as possible, at 3:00:10 p.m. according to a ship chronometer which was compared directly over the telephone with the time-marking clock at the Seismological Laboratory. The chronometer was slower than the clock by 9.6 seconds at $2: 28$ p.m.; by 9.8 seconds at $3: 13$ p.m.

The method of making. this comparison was as follows: in unison with the ticks of the chronometer, after sufficient practice, signals were spoken into the telephone mouthpiece which operated directly the timemarking relays at the Laboratory, in the way described above by Benioff. The final signal corresponded to the even minute indicated by the chro- 
nometer. The signals thus recorded were found to be evenly spaced. Their error is judged to be considerably smaller than one-tenth of a second.

A similar method of counting in unison with the ticks of the chronometer, after practice, was employed in timing the operation of the firing mechanism which detonated the explosive at the source. Therefore there is a possible error of, say, one-tenth of a second in the correlation of the chronometer time with the detonation time. This error could be either positive or negative, and as two persons co-operated, one calling signals and one operating the firing mechanism, it is possible that the resultant error is significantly less than one-tenth of a second, in case their personal errors were of opposite sign.

Knowledge of the firing time thus obtained, according to the chronometer, affords an independent determination of its value. The time of detonation as determined by this latter method is found to agree with that determined more directly within the limits of error introduced in reading the records. Therefore the firing time adopted is correct to the nearest tenth-second.

The first motion from the blast was recorded at Pasadena 2.4 seconds, at Mount Wilson 2.7 seconds, after the time of firing. A phase which resembles $\bar{S}$ but which is found to have too slow a velocity was recorded at Pasadena 4.9 seconds, at Mount Wilson 5.0 seconds, after the time of firing. For both these phases the times given for Mount Wilson may be in error by two-tenths of a second.

The site of the blast was distant from Pasadena between 12.5 and 13.0 kilometers ( 7.8 - to $8.0+$ miles), and from Mount Wilson between 13.2 and 13.5 kilometers (8.2- to $8.4-$ miles). Therefore the velocity of the first motion to reach Pasadena is 5.21 to 5.42 kilometers (3.2+ to 3.4- miles) per second. At Mount Wilson the corresponding values are 4.55 to 5.40 kilometers $(2.8+$ to 3.4 - miles) per second. For the phase which resembles $\bar{S}$ the velocities are found to be for Pasadena 2.55 to 2.60 kilometers (1.6 \pm miles) per second, for Mount Wilson 2.54 to 2.81 kilometers $(1.6-$ to $1.7+$ miles) per second.

Still other, later, apparent phases - if real, obviously arrivals of waves traveling with low velocities-were observed at both stations.

\section{The Victorville Blast}

Throngh the courtesy of $\mathrm{Mr}$. Robinson we were given adequate notice of the plan for firing this major blast so that we were able to prepare for a refined determination of the time of detonation.

At the quarry a wire was buried in the rock in the immediate prox- 
imity of the explosive so that its rupture would break an electric circuit at the effective instant of explosion. The interval between the breaking of the wire and the generation of the elastic waves in the rock seems certainly negligible. For the latter the time of rupture of the wire is probably better than the time of closing of the firing switch would be. The charge consisting of a little more than twenty tons of high explosive, ${ }^{2}$ buried in 141 holes ranging in depth from 13 to 52 feet (4- to 16 - meters) with individual charges of from 25 to 700 pounds (11 to 315 kilograms, approximately) over an L-shaped area about 340 feet (104- meters) north and south by some 480 feet (146 meters) east and west, was detonated effectively as one single charge by the closing of the switch, at a time when radio-code signals were being received and recorded automatically at the Seismological Laboratory at Pasadena, at each of the auxiliary stations of the local group, and at a temporary recorder at the site of the blast. Thus, at the temporary recording station at the quarry, the time of breaking of the electric circuit by the action of the blast was registered as a sudden offset in the line of the recording of the dots and dashes of the code message. This time can thus be determined accurately at the other stations by comparison.

Also a vertical-component shock-detector was installed at the cement plant near Victorville, 8.5 kilometers (5.3- miles) southwest of the quarry, to determine the time of arrival at this point of the shock from the blast. This time was communicated over the telephone to Pasadena, where it was recorded automatically on the seismograms by action of the regular time-marking relays, by the method described above in connection with the Arroyo Seco blast. This somewhat less accurate method was employed primarily as a safeguard, in case of failure of the timing at the site of the blast. However it affords a check on time at the origin and a determination of the time occupied by the shock wave in traversing the short distance from the quarry to the temporary set-up near Victorville. This interval can be determined within two to three hundredths of a second.

The geographic co-ordinates of the site of the blast were determined from data furnished by the Superintendent of the quarry to be, approximately, $\phi=34^{\circ} 37: 88 \mathrm{~N}, \lambda=117^{\circ} 16.35 \mathrm{~W}$. The limits of error are small but indeterminate.

\footnotetext{
2 Giant Powder Company's Quarry Special No. 70, a low-density nitrate of ammonia explosive (weight strength comparable to 70 per cent nitroglycerine, but bulk strength equivalent to 30.6 per cent only), with velocity of detonation of 5,500 feet per second, according to data supplied by the company.
} 
The geographic co-ordinates of the temporary station at the cement plant near Victorville were determined from data furnished by Mr. Hubbard of the Southern Sierras Power Company to be, approximately, $\phi=34^{\circ} 33.22 \mathrm{~N} ., \lambda=117^{\circ} 18.05 \mathrm{~W}$. Again, the limits of error are small but indeterminate.

The distance between the site of the blast and this temporary set-up at the cement plant, carefully measured from the map, is 8.5 kilometers (5.3- miles).

From the radio-code record written at the quarry, which fixed very exactly the time of the breaking of the wire, and the radio-code record written at Pasadena, which fixed very exactly the time of the arrival of the shock at the temporary station near Victorville, this interval-the time occupied by the shock wave in traveling from the quarry to the shock-detector-is found to be 1.65 to 1.7 - seconds. The corresponding velocity is, very nearly, 5.0 to 5.15 kilometers ( 3.1 to 3.2 miles) per second. The path traversed is in crystalline rock practically throughout, starting in a relatively small body of crystalline limestone which is surrounded by granite.

Following the arrival of the first motion, the records written at Riverside, Mount Wilson, and Pasadena show numerous changes in amplitude and period (or in both at about the same instant), some of which correspond to significant phases, while others probably are fortuitous. The measured times of the beginning, and of the succeeding phases or changes of motion, are given below. At Haiwee and at Tinemaha the registered amplitudes are very small, and indications of change of motion are few and uncertain. The stated distances from the place of the blast to the stations were calculated.

TABLE I

\begin{tabular}{|c|c|c|c|c|c|}
\hline & & $\begin{array}{l}\text { Phase } \\
\text { Charac- } \\
\text { teristic }\end{array}$ & Component & $\begin{array}{c}t-t_{0} \\
\text { sec. }\end{array}$ & $\begin{array}{l}\text { Apparent } \\
\text { Velocity } \\
\mathrm{km} . / \mathrm{sec} .\end{array}$ \\
\hline Riverside & (1) & $i$ & $N, E$ & 11.9 & $6.0-$ \\
\hline$\Delta$ & (2) & $e$ & $N, E$ & 12.3 & $5.8+$ \\
\hline \multirow[t]{9}{*}{$71.5^{*} \mathrm{~km}$} & (3) & $i(\bar{P} ?)$ & $N, E$ & 13.4 & $5.3+$ \\
\hline & (4) & & $E$ & 14.3 & $5.0-$ \\
\hline & (5) & & $N$ & 15.4 & $4.6+$ \\
\hline & (6) & & $N$ & 15.9 & $4.5^{\circ}$ \\
\hline & (7) & & $N$ & 17.6 & $4.0+$ \\
\hline & (8) & $i$ & $E$ & 20.7 & $3.5-$ \\
\hline & (9) & $Q ?$ & $E$ & 21.9 & $3.3-$ \\
\hline & (10) & $\bar{S} ?$ & $N$ & 22.8 & $3.1+$ \\
\hline & (11) & $R$ ? & $N$ & $23.9+$ & $3.0-$ \\
\hline
\end{tabular}

* With an uncertainty of about five-tenths of a kilometer. 
TABLE I-Continued

Mount Wilson

$\Delta$

$84.5^{*} \mathrm{~km}$.

\begin{tabular}{|c|c|c|}
\hline & $\begin{array}{r}(4) \\
(5) \\
(6) \\
(7) \\
(8) \\
(9) \\
(10) \\
(11) \\
(12) \\
(13) \\
(14) \\
(15)\end{array}$ & $\begin{array}{l}e \\
i \\
i \\
e \\
e \\
e \\
e \\
e\end{array}$ \\
\hline $\begin{array}{c}\text { Pasadena } \\
\Delta \\
98.3^{*} \mathrm{~km} .\end{array}$ & $\begin{array}{l}(1) \\
(2) \\
(3) \\
(4) \\
(5) \\
(6) \\
(7) \\
(8) \\
(9) \\
(10) \\
(11) \\
(12) \\
(13) \\
(14) \\
(15)\end{array}$ & $\begin{array}{c}i \\
i(\bar{P} ?) \\
e \\
e\end{array}$ \\
\hline
\end{tabular}

Haiwee

$\Delta$

$178.9^{*} \mathrm{~km}$.

Tinemaha

$\Delta$

$287.8 * \mathrm{~km}$.
(1)

(2)
Component

$$
\text { Phase }
$$$$
\text { teristic }
$$

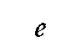

$$
\text { e }
$$

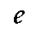$$
\text { e }
$$

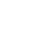

$i$

$e$

e

$\mathcal{L}$

$e$

\section{$i$}

$(\overleftarrow{P} ?)$

e

$$
\begin{gathered}
N \\
N, E \\
N, E \\
E \\
N, E \\
N, E \\
N, E \\
E \\
N, E \\
N \\
E \\
N \\
E \\
N
\end{gathered}
$$$$
N, E
$$$$
E, Z
$$$$
Z
$$

$N ?, E, Z$

$N, E, Z$

$Z$

$N, E, Z$

E

$$
Z
$$

$N, Z$

$N, E, Z$

$N, Z$

$N, Z$

E

E, Z

$Z$

$N$

E

\section{$E$}

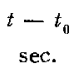

$15.2+$

16.0

$17.0-$

$17.3+$

17.7

$18.2-$

18.8

$18.9-$

20.8

$23.4+$

25.2

$25.4 \pm$

26.4

$26.6-$

28.6

16.7

$17.8 \pm$

$18.4 \pm$

$19.5+$

24.0

$28.9 \pm$

29.2

$30.2-$

$31.2+$

$32.1+$

$33.0+$

$34.0 \pm$

34.3

$36.1+$

$37.2+$

$35.9 \pm \mathrm{I} / 2$

57.1

$80.4 \pm 1 / 2$

$84.4 \pm x / 2$
Apparent $\mathrm{km}$./sec.

5.6-

5.3

5.0

4.9

4.8

4.7

4.5

$4.5-$

4.1

$3.6+$

$3.4-$

$3.3+$ 3.2

$3.2-$ 3. $0-$

$5.9+$ $5.55 \pm$ 5.4$5.0+$ 4.1

$3.4+$ $3.4-$ 3.25 3.15 $3.0+$ $3.0-$ $2.9-$ $2.8+$ $2.7+$ $2.6+$ $5.0-$ $3.1+$

$3.6 \pm$ 3. $4+$

* With an uncertainty of about five-tenths of a kilometer.

Small Blasts Near Eagle Rock

During the months of July and August, 1931, a few small blasts were fired in the course of excavation at the base of a large outcrop well 
known locally as the Eagle Rock, near the suburb of that name, distant 1.34 kilometers $(0.8+$ mile $)$ from the Seismological Laboratory and 14.6 kilometers $(9.1$ miles) from the station on Mount Wilson. Of these, three were large enough to register, barely, at the latter station and two, on July 8th and August 11th, were sufficient to permit determination of arrival-time. In both, the first motion reached Mount Wilson 3.2 seconds after its arrival at Pasadena, and at Mount Wilson there is also a phase 5.1 seconds later than the time of beginning at Pasadena.

For practically the whole distance between the source and the Seismological Laboratory the rock is granitic in character, deeply weathered but in situ. If the value for velocity indicated by local experience, 5.0 kilometers per second, is taken, the transmission-time is 0.27 of a second. Reasonable departures from this value for the assumed velocity will not make this interval appreciably different from three-tenths of a second. Accordingly the transmission-times to Mount Wilson for the two principal phases recorded there are 3.5 and 5.4 seconds, corresponding to apparent velocities of $4.2-$ and $2.7+$ kilometers $(2.6$ and 1.7- miles) per second.

As results of the measurements reported above we find, in the case of the Victorville blast of September 12,1931, except as noted otherwise:

1. The apparent velocity of the motion first registered at Riverside and at Pasadena is surprisingly high. The values found are, respec-

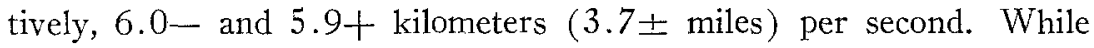
small, the difference in apparent velocity thus observed along these two different paths may prove real. In this connection, if velocity is determined in the present case by the method unavoidably employed in the former paper, namely, division of the difference in distance between the two stations by the time interval between the arrivals of the first motions, a value of 5.58 kilometers per second is obtained. This lower value for velocity is a necessary consequence of the difference in apparent velocity just noted. This shows that values of velocities obtained by this method of differences are less accurate than those obtained when the origin-time is known.

The velocities $5.9+$ to $6.0-$ are higher than those previously determined for granitic rock in this region. Along the way from the quarry both to Riverside and to Pasadena, excepting isolated, relatively thin, surface bodies of wash gravel which can hardly be involved significantly in the wave-transmission, the wave-paths traverse a complex of crystalline rocks known to be granitic in nature at the surface for 
all or practically all of the distance. When reasonable values for velocity in the underlying materials are assumed, attempts to account for the high wave-speed here found in the way now usual, by refraction of the wave-motion along a broken path into and out of a lower medium (or media) characterized by higher velocity, are found by calculation to indicate much too shallow a depth for the base of the granitic rock (here visible at the surface and also to depths of two kilometers [1.3上 miles] and more in canyons and along mountain fronts and escarpments).

Consequently no satisfactory explanation has occurred to us to account for these velocities. However, the following suggestion, dubious as it seems, cannot be excluded from consideration, namely, the assumption of a body of rock wholly beneath the surface but near to it through which these waves passed with sufficiently high velocity. Were such the explanation, it is clear that the waves transmitted to Riverside should traverse a longer segment, proportionately, in the medium of higher velocity than those transmitted to Pasadena, since the apparent velocity is higher for the waves which reached Riverside. For obvious reasons, the suggestion of a special explanation such as this is submitted with great reluctance, particularly since no rock material possessed of the requisite properties is known, or indicated in any other way, along either of the paths involved. It must be noted, however, that in a neighboring district, to the north and west of the Seismological Laboratory, the rock anorthosite is found at the surface over an area of some 350 square kilometers (140- square miles). ${ }^{3}$ The velocity of longitudinal waves in anorthosite has been calculated to be 5.9 kilometers $(3.7$ - miles) per second." However, a medium characterized by a still higher velocity than this would be required unless the paths traversed lay at deplh in anorthosite for practically the whole distance in both cases-a most improbable circumstance.

The excess of the velocities found over that normal for granitic rock in this region is considered well outside the allowable limits of error due to registration, interpretation, and measurement, and this seems confirmed by the registration of waves traveling with more normal velocities, as will be seen in what follows.

2. At Mount Wilson and Pasadena there is clear indication of a

${ }^{3}$ William J. Miller, "Anorthosite in Los Angeles County, California," Bulletin of the Geological Society of America, 39, 164, 1928.

« H. Reich, "Eigenschaften der Gesteine," "Handbuch der Geophysik," 6, 30, Berlin, 1931. 
wave traveling with the apparent velocity of approximately 5.55 kilometers ( 3.45 miles) per second, which is the normal velocity found in this region in local earthquakes for longitudinal waves traversing granitic rock.

It is to be noted that a straight line from the quarry to Pasadena passes within about 1.6 kilometers ( 1 mile) of the station on Mount Wilson. Consequently the rock materials along these two paths must be nearly or quite identical. Nevertheless the fast wave (1) is not definitely registered at Mount Wilson.

3. There is clear indication also at three stations-Riverside, Mount Wilson, and Pasadena-of a wave traveling with the apparent velocity of 5.4 kilometers (3.36- miles) per second, or slightly less. As recorded at Pasadena this wave is conspicuously larger in amplitude than either of the phases ( 1 and 2 ) just noted. This wave is probably the same as the first motion recorded at Mount Wilson and Pasadena in the case of the blast in the Arroyo Seco. Experience indicates that a wave traveling with this apparent velocity registers as a most conspicuous phase in the preliminary motion with blasts set off in this region. This, therefore, should be correlated with the velocity of 5.50 kilometers per second given in our previous paper. ${ }^{5}$ This later value is to be preferred since the earlier value, 5.50, determined chiefly on a statistical basis, also involves conclusions from data of the previous blast at Victorville now rendered uncertain, because it is now doubtful whether the phases then identified as the same at Riverside and Pasadena are actually the same motion.

4. At five places-including the emergency installation near Victorville, and the regular stations at Riverside, Mount Wilson, Pasadena, and Haiwee-there appears to be excellent indication of a wave traveling with the apparent velocity of $5.0+$ kilometers $(3.1+$ miles $)$ per second. This corresponds very well, too, with the velocity of 5.08 kilometers per second for the first wave registered at Pasadena with definiteness and certainty in the case of the very large blast at Corona. ${ }^{6}$ Since this wave seems now to have been observed in this region on two different occasions and at six different distances ranging from about 8.5 to 179 kilometers ( 5.3 - to $110+$ miles) it seems legitimate to conclude that in this region there probably is found a wave which travels at or near the surface with a velocity of 5.0 kilometers per

\footnotetext{
5 Wood and Richter, op. cit., p. 42.

${ }^{6}$ Ibid., p. 41.
} 
second. This makes doubtful the explanation previously offered to account for the wave having this speed in the case of the blast at Corona. ${ }^{7}$

5. There is fair indication at the three nearer stations-Riverside, Mount Wilson, and Pasadena-of a wave traveling with an apparent velocity of about 4.1 kilometers ( 2.55 miles) per second. It is possible that this wave is the same as that first to arrive at Mount Wilson in the case of the Eagle Rock blasts. So far no good explanation for a wave with such velocity has occurred to us.

6. At Riverside and Pasadena, and possibly at Tinemaha, there is good indication of a wave traveling with an apparent velocity of about 3.5- kilometers (2.2- miles) per second, approximately. A wave seemingly the same was observed on the Riverside record of the earlier blast at Victorville.

7. There is dubious indication at Mount Wilson and Pasadena of a wave traveling with an apparent velocity of 3.4 kilometers $(2.1+$ miles) per second, or less.

8. At three stations-Riverside, Mount Wilson, and Pasadenathere is fair indication of a wave traveling with an apparent velocity of 3.25 kilometers $(2.0+$ miles $)$ per second, approximately. This perhaps may be correlated with the value 3.21 kilometers $(2.0-$ miles $)$ per second determined in connection with the Corona blast, although the latter might equally well be correlated with the velocity of $3.15 \mathrm{kilo}$ meters per second. The value 3.25 corresponds also with the velocity for transversal waves in local earthquakes.

9. There is indication at four stations-Riverside, Mount Wilson, Pasadena, and Haiwee-of a wave traveling with an apparent velocity of about 3.15 kilometers ( 1.96 miles) per second.

10. There is good indication at three stations-Riverside, Mount Wilson, and Pasadena-of a wave traveling with an apparent velocity of 3.0 kilometers (1.9- miles) per second, or possibly slightly less. Very nearly, this is the velocity found locally for the Rayleigh wave by Gutenberg. ${ }^{8}$

11. Finally, at Pasadena the records exhibit motion indicating waves traveling with apparent velocities near to 2.7 kilometers ( 1.7 - miles) per second. Velocities very near to this value were found in the previous study of local blasts, and also in the blasts at the Eagle Rock and in the Arroyo Seco.

I Ibid., pp. 43-44.

${ }^{8}$ B. Gutenberg, "Travel-Time Curves at Small Distances and Wave Velocities in Southern California," Beiträge sur Geophysik, 35, 34, 1932. 


\section{Transmission-Time Curves}

Transmission-time curves controlled by the data of measurement are shown in the diagram, Figure 1 , in which values of distance, $\Delta$, in kilometers are indicated on the axis of abscissas and values of time, $t$, in seconds on the axis of ordinates - the latter, also, on an enlarged scale for the smaller distances. In the present Victorville blast the time at the origin is known with high precision, and effectively it is known with possibly equal accuracy for the Arroyo Seco blast. For the Eagle Rock blast it is assumed, but any error thus introduced is very small. Consequently the time $t_{0}=0$ is taken as the origin of ordinates, and the plot of points and lines shows transmission-times at the indicated distances.

In order to compare more readily the results of the present study with those of the earlier one-in which only the time of the first motion, interpreted in most instances as $\bar{P}$, was known (except in the case of the Corona blast) - a plot was constructed on the same scale as in the former case showing points and lines referred to $t_{\vec{p}}=0$ as origin of ordinates. The agreement thus brought out was surprisingly close. extending even to peculiar deviations from expectable values. However, though much more precise, the data of the present investigation refer to fewer values for $\Delta$, and care must therefore be exercised in emphasizing the correspondences, except in the more obvious and more thoroughly established cases. For example, apparent confirmation at one point of the reflected phase, $\bar{P}_{15} \bar{S}$, previously suggested is seen in the present case to be explained at least equally well and probably much better as a point on the transmission-time curve for waves having the velocity of 4.1 kilometers per second. The data of the present study lend no support, other than this one correspondence of probably fortuitous nature, to the occurrence of phases indicating the reflected waves, $\bar{P}_{15} \bar{S}, \bar{P}_{15} \bar{P}$, and $\bar{P}_{25} \bar{P}$, hypothesized and discussed in the previous paper. In particular, the wave identified as $\bar{P}_{15} \bar{S}$ in the case of the San Gabriel dam blast as registered at Pasadena can probably be explained as the wave traveling with the apparent velocity of 3.0 kilometers per second.

The record of the blast at the Victorville quarry (September 12, 1931) written by the short-period vertical-component seismometer at Pasadena, distant 98.3 kilometers, is shown in Figure 2, enlarged two times, very nearly, so that the interval between the beginnings of successive minute-marks is, very closely, 120 millimeters. Transverse lines have been drawn to indicate phases, arrival-times, etc., on the record. However, the beginning of that "minute-mark" which immediately precedes the motion due to the blast is, in reality, the time of the arrival 


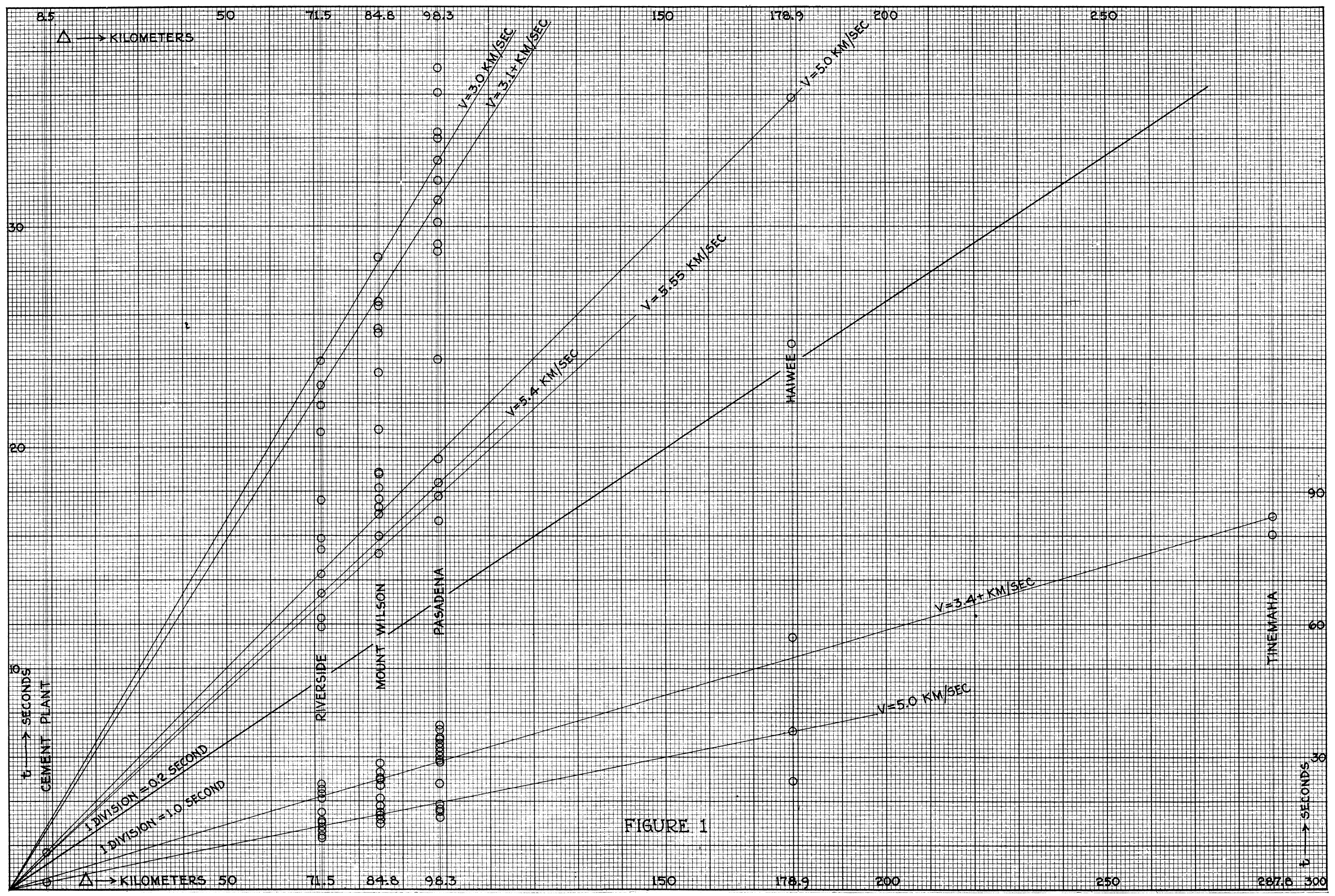

FIG. 1.-Transmission-time curves: Lower part, $\Delta$ in kilometers, time in seconds; upper part, $\Delta$ in kilometers, time in fifth-seconds. 


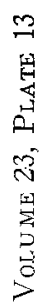

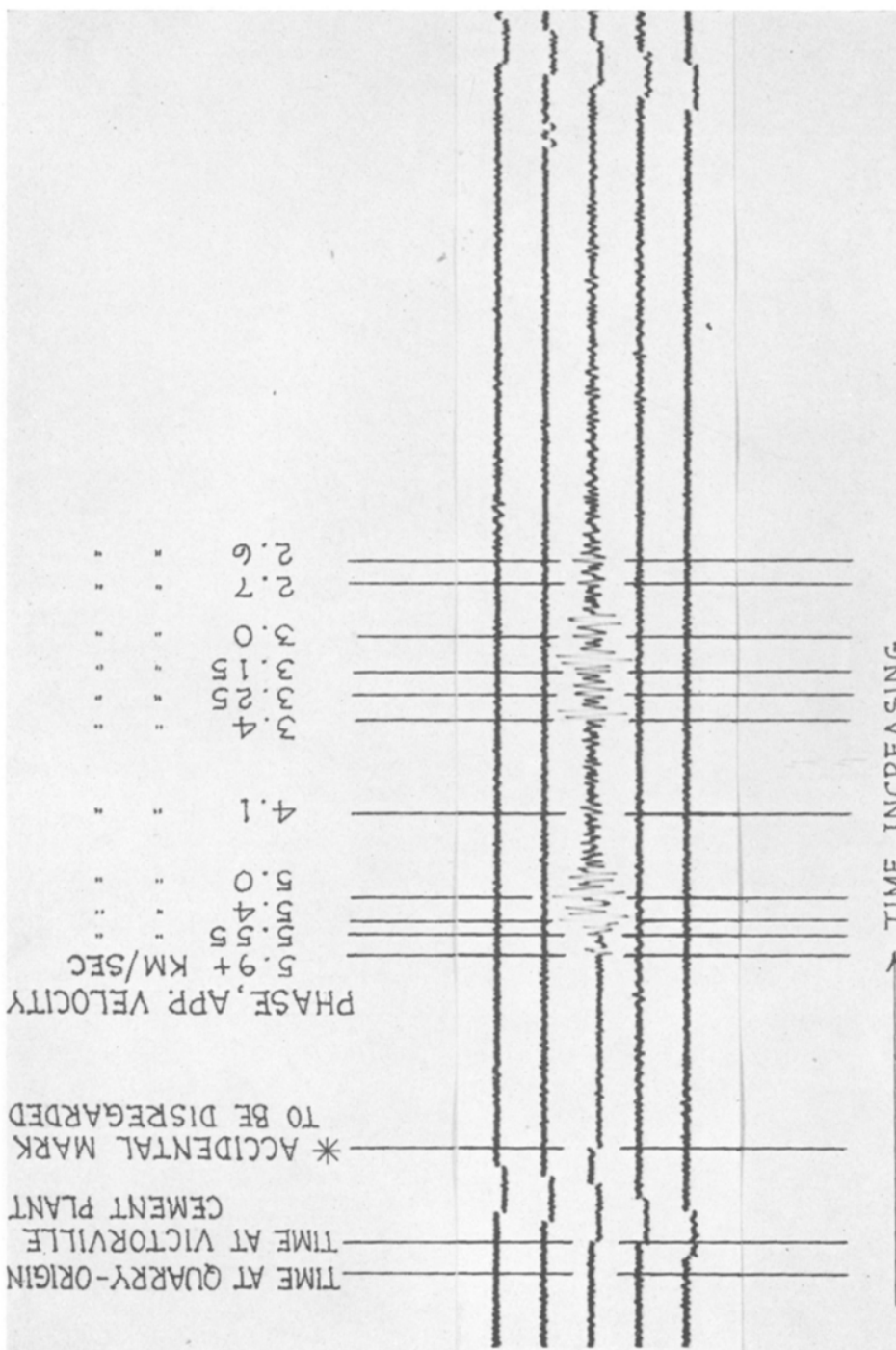

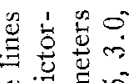

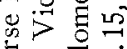

击的

क्ष

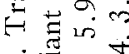

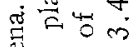

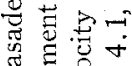

त

范范

峞芯艺

ह तु है

है

跑

苞范总

可落

虽

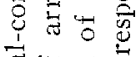

矛莒

氖蛋

s...

的

牙苋

弯家

范然

:

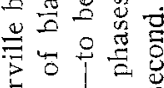

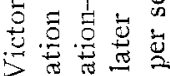

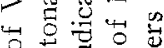

O

若要

进焉

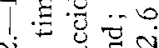

v...

苑

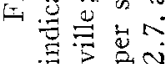


of the disturbance at the cement plant near Victorville transmitted over the telephone to Pasadena (by the method described), where it operated the regular time-marking relay a fraction of a second before the relay would have been operated by the station contact-making time clock. For this reason this particular "minute-mark" is longer than the other similar marks. A second or so after this "minute-mark" had ended, the timemarking relay was again operated by accident, displacing the line of recording downward. This time, indicated by the transverse line marked with the asterisk (*), has no significance and should be disregarded. The line of recording again returned to its normal position at a point near that indicated by the phase-beginning which corresponds to the apparent velocity 5.4 kilometers per second. Notwithstanding the slight complication thus introduced, the phase is real and well established. This is supported by findings at other stations, as well as on other records at Pasadena.

The transverse line farthest to the left, preceding that which is drawn to indicate the time of arrival at the cement plant, indicates, very closely indeed, the time of detonation of the blast. Phases shown on the record appear at intervals, indicated by successive transverse lines, corresponding to the following apparent velocities, namely, 5.9+, 5.55, $5.4,5.0,4.1,3.4,3.25,3.15,3.0,2.7$, and 2.6 kilometers per second.

To explain the numerous apparent phases listed above it would be possible, but not judicious, to hypothesize division of the upper part of the crust into horizontal layers having suitable velocity characteristics. Our knowledge of the rock materials and geologic structures over the area involved makes such an explanation very improbable, especially since calculations made on such a basis lead to values for the thickness of such layers not only too small to be reasonable, but actually smaller than the visible thickness for the case of the uppermost of such layers.

On the other hand the terrane, made up of plutonic and crystalline metamorphic rocks practically everywhere, is not homogeneous, but consists of large irregular bodies of rocks which have different properties and characteristics in many cases. In itself, when an investigation of velocity is conducted with high precision and in very minute detail, this irregular, moderately large-scale inhomogeneity in the material should give rise to numerous slightly different wave-paths with a different average apparent velocity along each. Though not to be emphasized, in part this may prove to be a true explanation for some of the large number of apparent phases observed.

Stress may be laid upon the particular velocity of $5.0+$ kilometers 
( 3.15 miles) per second. Its wide occurrence seems to indicate that it is a general phenomenon characteristic of this local region, at least. It finds reasonable explanation as a wave running near the surface, probably beneath the zone of weathering and of pronounced surface irregularity. Of course it is by no means demonstrated that this is its true explanation.

At Mount Wilson this phase is followed immediately by several apparent phases not found elsewhere. This phenomenon may be accounted for, perhaps, by diffraction of this motion under the obstacle presented by the marked topographic irregularities immediately to the north and east of this station. For example, within a distance of about four kilometers (about 2.5 miles) to the northeast of the summit of the mountain (elevation $=1,742$ meters or about 5,700 feet) the east-west trending canyon of the West Fork of the San Gabriel River is cut down to an elevation of only about 760 meters (about 2,500 feet).

The well-marked wave traveling with an apparent velocity of about 3.0 kilometers per second may conceivably be the transverse wave corresponding to the longitudinal wave which has a velocity of $5.0+$ kilometers per second, but, as already pointed out, the Rayleigh wave also has a velocity of about 3.0 kilometers per second in this region. This circumstance may perhaps account for the somewhat complicated aspect exhibited by the records in the vicinity of this phase.

The waves traveling with apparent velocities of about 2.7 kilometers per second must not be overlooked, as these have been most conspicuous at short distances in a number of cases. It may be possible that these are transverse waves which traverse still more superficial paths, possibly in the zone more or less affected by weathering.

To explain the most rapid longitudinal waves we have referred above, very reluctantly, to a special hypothesis-a body of rock with high velocity properties buried at a slight depth. This hypothesis would call for a correspondingly rapid transverse wave. A wave with such a velocity is observed, namely, that traveling with the apparent velocity of 3.5 kilometers per second. Before proceeding further we wish explicitly to state that this hypothesis appears contrary to geological expectation. It is not completely impossible, however, and consequently it leads to further deductions which are stated here in order that it may be clear that they have not been overlooked. Obviously no emphasis is placed upon these apparent correspondences.

If such a body is immersed in rock of granitic character and does not extend to too great depth (or have too great horizontal dimensions), there exists the following possibility. Waves-direct, refracted, or dif- 
fracted-may pass above, below, or to one side of the mass and thus reach the station and be registered later than the fast waves which, by hypothesis, traverse the body. Thus the waves with apparent velocities of 5.55 and 3.25 kilometers per second might be longitudinal and transverse waves which have passed through granitic rock below the body, so approximating the speed of earthquake waves. An analogous explanation could account for the waves traveling with apparent speeds of 5.4 and 3.15 kilometers per second, either above the body or to one side of it, with consequent lower velocities. This hypothesis would also explain the large amplitudes written at Pasadena by the sensitive vertical seismometers for the motion traveling 5.4 kilometers per second, as might be expected from a wave traversing a direct path, while those traveling 6.0 - to $5.9+$ and 5.55 kilometers per second wrote smaller amplitudes, such as might be expected in case of refraction or diffraction.

On the other hand, beside the geological improbability of the hypothesis, it fails in other expectable consequences. Although Mount Wilson is practically in the direct path between the quarry site and the Seismological Laboratory-so that wave-paths in the two cases cannot differ essentially except in the immediate approach to the mountain summit-no sufficient indication is to be found on the records written at Mount Wilson of the fast longitudinal wave with a velocity of $6.0-$ to $5.9+$ kilometers per second, while the corresponding transverse wave, if any phase can be identified as such, arrives too early. This is surprising, to say the least.

Moreover, there is indication of an additional wave having an apparent velocity of $3.3+$ to $3.4-$ kilometers per second which can only be explained-on this special hypothesis-by still more special assumptions. Also, this hypothesis offers no explanation for the wave indicated to have a velocity of 4.1 kilometers per second. It must be stated, however, that no explanation has yet been found for this wave in any case. It is worth repeating, therefore, that this special hypothesis, despite some apparent correspondences, is considered improbable for geologic reasons-notwithstanding the fact that some heterogeneity in the rock substance, involving irregular bodies of large bulk, is positively known.

\section{SUMMARY}

Investigation of several blasts subsequent to those considered in our previous study, and in particular a major blast set off near Victorville, California, on September 12, 1931, has yielded results as follows. 
1. In two cases the time of detonation was determined (a) very accurately in the case of the blast near Victorville by a precise method, and (b) probably with substantially equal accuracy in the case of the blast in the Arroyo Seco, though the method employed was inherently less precise.

2. Phases, or definite changes in registered motion, have been recognized and measured which appear to correspond to successive arrivals of waves traveling, apparently, along direct paths with different apparent velocities, as follows: $6.0-$ to $5.9+, 5.55,5.4-, 5.0+, 4.1$, $3.5-, 3.4-, 3.25,3.15,3.0-, 2.7 \pm$ kilometers per second.

3. In the present study no positive evidence has been found to indicate reflected waves, or waves refracted along deeper layers. Phases considered in the previous study to indicate such waves are now found to be susceptible of alternative explanations.

Difficulties have been encountered, as discussed in the body of the paper, in the interpretation and satisfactory explanation of certain of the very numerous apparent phases, particularly those which appear to indicate waves with apparent velocities of $6.0-$ to $5.9+$, and $4.1 \mathrm{kilo-}$ meters per second.

From this it is again clear that further opportunities for similar investigations are of great importance. For this reason, and also in order that blasts of moderate, or larger, magnitude may not be included in lists of small local earthquakes, it is suggested that all such blasts set off in the region of Southern California should be reported to the Seismological Laboratory at Pasadena-and, whenever practicable, sufficiently in advance to permit preparations for thorough study.

\author{
Carnegie Institution of Washington \\ SeIsmological Research \\ Pasadena, California \\ July 1,1932
}

